\title{
Imprinted DLK1-DIO3 region of 14q32 defines a schizophrenia-associated miRNA signature in peripheral blood mononuclear cells
}

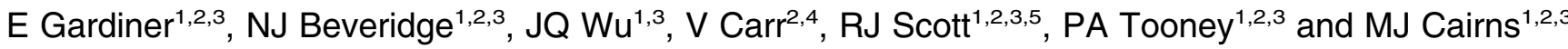 \\ ${ }^{1}$ School of Biomedical Sciences and Pharmacy, The University of Newcastle, Callaghan, NSW, Australia; ${ }^{2}$ Schizophrenia \\ Research Institute, Sydney, NSW, Australia; ${ }^{3}$ Centre for Brain and Mental Health and Centre for Information-Based Medicine, \\ University of Newcastle and Hunter Medical Research Institute, Newcastle, NSW, Australia; ${ }^{4}$ School of Psychiatry, \\ University of New South Wales, Sydney, NSW, Australia and ${ }^{5}$ Hunter Area Pathology Service, Newcastle, NSW, Australia
}

\begin{abstract}
MicroRNAs (miRNAs) regulate gene expression at the post-transcriptional level and are important for coordinating nervous system development and neuronal function in the mature brain. We have recently identified schizophrenia-associated alteration of cortical miRNA biogenesis and expression in post-mortem brain tissue with implications for the dysregulation of schizophrenia candidate genes. Although these changes were observed in the central nervous system, it is plausible that schizophrenia-associated miRNA expression signatures may also be detected in non-neural tissue. To explore this possibility, we investigated the miRNA expression profile of peripheral blood mononuclear cells (PBMCs) from 112 patients with schizophrenia and 76 non-psychiatric controls. miRNA expression analysis of total RNA conducted using commercial miRNA arrays revealed that 33 miRNAs were significantly downregulated after correction for multiple testing with a false discovery rate (FDR) of $0 \%$, which increased to 83 when we considered miRNA with an FDR $<5 \%$. Seven miRNAs altered in microarray analysis of schizophrenia were also confirmed to be downregulated by quantitative real-time reverse transcription-polymerase chain reaction. A large subgroup consisting of 17 downregulated miRNAs is transcribed from a single imprinted locus at the maternally expressed DLK1-DIO3 region on chromosome 14q32. This pattern of differentially expressed miRNA in PBMCs may be indicative of significant underlying genetic or epigenetic alteration associated with schizophrenia.
\end{abstract}

Molecular Psychiatry (2012) 17, 827-840; doi:10.1038/mp.2011.78; published online 5 July 2011

Keywords: biomarker; gene silencing; microRNA; PBMCs; schizophrenia; 14q32

\section{Introduction}

Schizophrenia is a severely debilitating and complex neuropsychiatric disorder afflicting nearly one in 100 people throughout life. ${ }^{1}$ Although some gross neuroanatomical and histological features have been associated with schizophrenia, none are consistent enough to be considered diagnostic. ${ }^{2-7}$ The scarcity of tangible pathology means that clinical diagnosis is based on descriptive criteria and requires persistent or episodic presence of certain symptoms over a defined period with associated disability and exclusion of other psychiatric conditions. As early intervention in schizophrenia is thought to be important in improving outcome, any delay in diagnosis or misdiagnosis owing to the inherent limitations of clinical descriptors may have a negative prognostic impact. ${ }^{8,9}$

Correspondence: Dr MJ Cairns, School of Biomedical Sciences and Pharmacy, The University of Newcastle, University Drive, Callaghan, NSW 2308, Australia.

E-mail: murray.cairns@newcastle.edu.au

Received 31 October 2010; revised 27 May 2011; accepted 1 June 2011; published online 5 July 2011
Consequently, accessible biological markers are needed to improve the timing and accuracy of diagnosis, and identify individuals at very high risk of schizophrenia. This information may also provide the opportunity to tailor treatment to the individual and enable more effective early intervention. ${ }^{10-13}$ Despite having a strong genetic component, early expectations of a simple genetic diagnostic for schizophrenia have been thwarted as the heritability appears to involve a complex, heterogeneous mixture of common variants, each with small effect size. ${ }^{14}$

More recently, studies have attempted to move closer to the neuropathology of schizophrenia in an attempt to identify common pathways in the disorder. High-throughput gene expression analysis has revealed altered gene expression in post-mortem brain including the dorsolateral prefrontal cortex, superior temporal gyrus and amygdala, which are all functionally relevant to the pathology of schizophrenia. ${ }^{15-22}$ Although no single gene has been found to be consistently altered across studies or brain regions, most report the enrichment of pathways relevant to the putative neurobiology of schizophrenia. In many 
instances, the extent and shape of gene alteration in post-mortem brain may imply the involvement of aberrant regulatory or epigenetic influences. In support of this hypothesis, we recently reported changes in cortical microRNA (miRNA) biogenesis and expression in schizophrenia. ${ }^{23,24}$ These molecules strongly influence gene expression, particularly in the brain where they are thought to be involved in both neurodevelopment and in the regulation of synaptic structure and function. ${ }^{25-29}$

Although the pathophysiology of changes in cortical miRNA expression remains to be determined, it is plausible that alteration of miRNA expression extends beyond the brain and could provide useful peripheral biomarkers for schizophrenia that would be accessible for clinical use. miRNA molecules are highly stable ${ }^{30}$ and, owing to their regulatory function (predicted to regulate half of the human genome ${ }^{31}$ ), are arguably more informative and prognostic than gene expression. Certainly in the field of cancer biology, miRNA may be a more accurate predictor of tumor phenotype than its genotype. ${ }^{32,33}$ miRNA profiling of tissues and body fluids has been instructive in a variety of cancer types including chronic lymphocytic leukemia and lung, prostate, bladder and breast cancer. ${ }^{34-37}$ Perhaps more relevant to brain disorders like schizophrenia, miRNA profiling of whole blood in multiple sclerosis has revealed expression signatures associated with the disease and its remission status. ${ }^{38}$ Similarly, miRNA analysis in Alzheimer's disease has revealed significant patterns of altered expression in peripheral blood mononuclear cells (PBMCs) ${ }^{39}$ as well as in the cerebrospinal fluid and brain. ${ }^{40}$ PBMCs in particular represent an attractive alternative tissue for profiling active disease in living patients at statistically robust numbers. This accessible tissue can reflect global disease-associated changes in an underlying genetic disorder and may have special significance where immunological risk factors are believed to be involved. In schizophrenia, for example, prenatal maternal infection is thought to be an important risk factor ${ }^{41-44}$ that may leave immunologically relevant expression signatures in PBMCs.

In this study, we examined miRNA expression in PBMCs derived from a cohort of schizophrenia patients and non-psychiatric controls, and identified a significant schizophrenia-associated reduction in 83 miRNAs. A large proportion of this expression signature was derived from a cluster of 17 miRNAs residing in a single imprinted domain on 14q32. This discovery has implications for our understanding of epigenetic regulation and inheritance in schizophrenia, and may also have applications as a novel biomarker for the disorder.

\section{Materials and methods}

\section{Participant recruitment and clinical assessment protocol}

Participants, the majority of whom identified as Caucasian, were recruited by the Australian
Schizophrenia Research Bank and the Hunter DNA Bank. In this study, the cohorts consisted of 112 participants with a lifetime diagnosis of schizophrenia and 76 non-psychiatric controls that were deemed eligible for inclusion after assessment by qualified psychologists using the Diagnostic Interview for Psychosis. ${ }^{45}$ Participants were excluded if they were currently diagnosed with any organic brain disorders, substance dependence, brain injury that caused posttraumatic amnesia lasting $>24 \mathrm{~h}$, mental retardation (IQ $<70$ ), movement disorder or if they had electroconvulsive therapy within 6 months. These exclusion criteria were likewise used for non-psychiatric control subjects with the additional criterion that they had no personal or family history of either psychosis or bipolar disorder type $1 .^{46}$ In addition, participants were required to speak English, and were aged between 18 and 65 years. Participants gave informed consent for inclusion in the study protocol, as approved by the institutional research ethics committees. All cases reported using antipsychotic medication at the time of interview and blood draw. Demographic and clinical variables of the cohort are summarized in Table 1 and described in detail in Supplementary Table 1.

\section{Extraction of RNA and DNA from whole blood}

Whole blood $(20 \mathrm{ml})$ was collected from subjects and transported to the Australian Schizophrenia Research Bank for processing. PBMCs were extracted by centrifugation using Lymphoprep (Vital Diagnostics, Lincoln, RI, USA). Total RNA was extracted from PBMCs obtained using Trizol, as per the manufacturer's instructions (Invitrogen, Life Technologies, Carlsbad, CA, USA). RNA concentration was determined using a NanoDrop 2000 (Thermo Scientific, Delaware, ME, USA). Genomic DNA was extracted

Table 1 Summary statistics for clinical and demographic variables characterizing the schizophrenia and control cohort

\begin{tabular}{lc}
\hline Demographic/clinical variable & $\begin{array}{c}\text { Summary } \\
\text { statistics }\end{array}$ \\
\hline Diagnosis: SZ/CTRL & $112 / 76$ \\
Mean age & 39.4 \\
Gender: M/F & $101 / 82$ \\
Mean age at the onset of illness & 24.2 \\
Family history of schizophrenia (cases): & $41 / 55$ \\
present/none & \\
Family history of other psychosis (cases): & $49 / 47$ \\
present/none & \\
Mean duration of illness & 16.4 \\
Mean RQI & 9.3 \\
\hline
\end{tabular}

Abbreviations: CTRL, non-psychiatric control; F, female; $\mathrm{M}$, male; RQI, RNA quality indicator; SZ, schizophrenia. Family history of other psychosis, reports any other psychiatric mental illness in any first- or second-degree relative. 
from PBMCs using a standard salt extraction method and quantified by PicoGreen assay (Invitrogen, San Diego, CA, USA). The integrity of randomly selected genomic DNA was checked by agarose gel electrophoresis.

\section{$R N A$ integrity}

RNA integrity was assessed using an Experion microcapillary electrophoresis device according to the manufacturer's instructions (Bio-Rad, Hercules, CA, USA). The average RNA Quality Indicator for this cohort was 9.3. Samples with RNA Quality Indicator values $\geqslant 6.3$ were considered intact and therefore suitable for use in miRNA microarray experiments and quantitative real-time reverse transcription polymerase chain reaction (PCR)

\section{miRNA expression profiling}

Profiling of human miRNA expression (miRBase version 9.1) was achieved using the commercial miRNA microarray platform (Illumina, San Diego, CA, USA) as described previously. ${ }^{47}$ Microarray data was extracted and normalized with respect to the geometric mean of U44 and U49 small nucleolar RNA (snoRNA) expression. Analysis of variance was used for the evaluation of association between non-diagnosis variance (batch effects, gender and age) and miRNA expression. Age showed a significant correlation with miRNA expression and was therefore used as a covariate in the subsequent analysis. Differential expression analysis was performed using the significance analysis of microarray statistical analysis program (full academic version 2.23, website http://www-stat.stanford.edu/ $\sim$ tibs/SAM/). ${ }^{48}$ Normalized expression data for the differentially expressed miRNA is shown in Supplementary Table 2. Unsupervised hierarchical clustering was performed in Cluster (Stanford University, Palo Alto, CA, USA; Eisen et $a^{49}$ ) and a heat map visualized through Java Treeview V.1.1.1. ${ }^{50}$ Data were log transformed and median centered by genes. Genes and arrays were clustered, correlation un-centered, by average linkage clustering.

\section{Quantitative real-time reverse transcription PCR}

Validation of differentially expressed miRNA was performed by quantitative real-time reverse transcription PCR on a subset of the cohort consisting of 91 participants (57 schizophrenia, 34 non-psychiatric controls), similarly to that described previously. ${ }^{24}$ Briefly, 500 ng of sample RNA was treated with DNAse-I (Invitrogen, Life Technologies) and multiplex reverse transcription performed with Superscript II reverse transcriptase (Invitrogen, Life Technologies), a $3 \mathrm{nM}$ mix of miRNA sequence-specific primers and primers for U44 snRNA and U49 snoRNA (for primer sequences, see Supplementary Table 3). Seven miRNA were chosen for real-time validation on the basis of strong differential expression on the microarray and/or biological significance. Triplicate reactions were set up in a 96-well format using the epMotion 5070 automated pipetting system
(Eppendorf, Hamburg, Germany) and carried out using the Applied Biosystems 7500 real-time PCR machine. Relative miRNA expression was determined with respect to the geometric mean of U44 and U49 snoRNAs by calculating the difference between the average cycle threshold $\left(C_{t}\right)$ of the miRNA of interest and the geometric mean of the average $C_{t}$ values of housekeeping snoRNA for each sample $\left(\Delta C_{\mathrm{t}}\right)$. Data were not normally distributed (as determined by GraphPad Prism version 5.0); therefore, the significance of differential expression was determined using a Mann-Whitney $U$-test (PASW Statistics 18).

\section{Target prediction and functional pathway analysis}

Putative target genes for schizophrenia-associated miRNA identified in this study were predicted using the miRanda ${ }^{51}$ and TargetScan (release 5.1) ${ }^{52}$ search algorithms (http://www.microrna.org/microrna/home.do; http://www.targetscan.org/). These putative target genes were further filtered by selecting genes containing five or more predicted binding sites either by the same or multiple miRNA as these genes are most likely to be regulated by the differentially expressed miRNA. ${ }^{53}$ Pathway analysis was then performed on a combined list of targets from both algorithms (union), followed by a more stringent pathways analysis on those targets that were common to both miRanda and TargetScan (intersection) using WebGestalt Gene Set Analysis Toolkit V.2 (http://bioinfo.vanderbilt.edu/webgestalt/). ${ }^{54}$ Visualization of pathways and networks from this information was facilitated by the construction of an 'enrichment map' of significant pathways $(P<0.05$ Benjamini-Hochberg) containing seven or more genes per category (http://baderlab.org/Software/EnrichmentMap). ${ }^{55}$

\section{Analysis of copy-number variation}

Genomic copy-number status of the 14q32 region was investigated using commercial TaqMan copy-number assays (Applied Biosystems, Life Technologies, Carlsbad, CA, USA; Hs07397776_cn, Hs03879584_cn and Hs03889902_cn) corresponding to cytobands 14q32.2b, 14q32.2b and 14q32.31a, respectively (refer to Supplementary Figure 1 for details). Reactions were prepared as per the manufacturer's instructions using an EPMotion 5070 automated liquid handling device (Eppendorf) and carried out using an ABI7500 real-time PCR machine (Applied Biosystems). The CopyCaller software V.1.0 (Applied Biosystems) was used to calculate relative copy number at each of the three locations. Each sample was normalized to the copy-number reference assay (RNase P, part number 4316831 ), known to be present in two copies in a diploid genome.

\section{Results}

miRNA expression analysis

miRNA expression was analyzed in PBMCs of 112 patients with schizophrenia and 76 non-psychiatric controls using human miRNA array matrices (Illumina). After normalization and background 


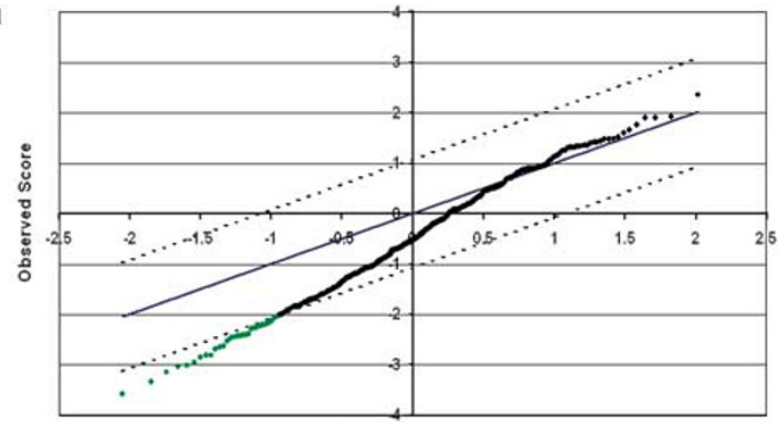

b

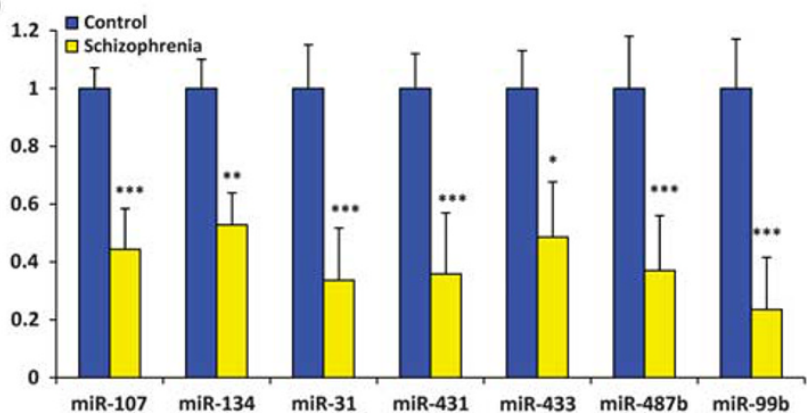

Figure 1 Schizophrenia associated microRNA (miRNA) expression in peripheral blood mononuclear cells (PBMCs). (a) Significance analysis of microarray (SAM) plot of differentially expressed miRNA in PBMCs from participants with schizophrenia $(n=112)$ compared with non-psychiatric controls $(n=76)$. The central solid blue line indicates equal expression and the upper and lower dashed black lines indicate levels for significantly altered expression (false discovery rate (FDR) of $0 \%$ ). (b) Quantitative real-time reverse transcription polymerase chain reaction (Q-PCR) validation of miRNA significantly downregulated by miRNA array analysis. Bars indicate mean fold change \pm s.e.m. of 91 samples (57 schizophrenia cases and 34 non-psychiatric controls). The control cohort is set at $1 .{ }^{*} P<0.05$; ${ }^{*} P<0.01$; ${ }^{*}{ }^{*} P<0.001$ by Mann-Whitney $U$-test.

subtraction, signals corresponding to 358 miRNAs or approximately $40 \%$ of the array content remained. Statistical analysis revealed 33 significantly downregulated miRNA at a false discovery rate (FDR) of $0 \%$ (Figure 1a) increasing to 83 at an FDR <5\% (Table 2). This included a number of brain-enriched miRNAs, miR-134, miR-128 and miR-181b. By contrast, there were no miRNAs that were significantly increased according to these criteria. Seven of the differentially expressed miRNA were further analyzed by quantitative real-time reverse transcription PCR in a representative sample consisting of 57 schizophrenia cases and 34 controls. miRNA expression was normalized to the geometric mean of two constitutively expressed snoRNAs U44 and U49. These results were highly concordant with the microarray analysis with all seven of the miRNAs confirmed to be significantly downregulated in schizophrenia compared with controls (Figure 1b) (two-tailed Mann-Whitney $U$-test). These included miR-31 (2.97-fold, $P<0.001)$, miR-431 (2.79-fold, $P<0.001$ ), miR-433 (2.06-fold, $P=0.017$ ), miR-107 (2.25-fold, $P<0.001)$, miR-134 (1.89-fold,
$P=0.007)$, miR-99b (4.24-fold, $P<0.001)$ and miR487b (2.06-fold, $P<0.001)$.

\section{Cluster analysis of schizophrenia-associated miRNA}

The miRNAs shown to be associated with schizophrenia in the microarray analysis were also subjected to hierarchical clustering (Figure 2). This segregated the participants into two main groups in which reduced expression was enriched within the schizophrenia cohort (Figure 2, left side) in contrast to the majority of controls, which were visually distinguished by their relatively higher expression (Figure 2, right side). Strikingly, a cluster of 17 of the most substantially downregulated miRNAs were also structurally associated by their genomic position on the long arm of chromosome 14 (14q32). These miRNA all reside within two closely neighboring segments each spanning about $40 \mathrm{~kb}$ and separated by $\sim 110 \mathrm{~kb}$, at $14 \mathrm{q} 32.2$ and $14 \mathrm{q} 32.31$ (Figure 3). This cluster encodes at least 48 miRNA genes, ${ }^{56,57}$ of which 30 mature miRNAs were expressed in the PBMCs. This indicated that approximately $53 \%$ of the miRNAs expressed at this locus were significantly downregulated in schizophrenia. Moreover, when we examined miRNAs expressed in this cluster that were not significantly altered after correction for multiple testing, a further 10 miRNAs or $33 \%$ (including miR-493*, miR-665, miR-379, miR-411, miR-376a, miR-376b, miR-376c, miR-495, miR-539, miR-889) also displayed an average reduction in schizophrenia consistent with the trend seen in the majority of miRNAs expressed from this region. This pattern of expression among the clustered miRNAs associated with schizophrenia was also highly consistent within individuals, suggesting that their transcription may be under the influence of shared regulatory mechanisms.

\section{Copy-number analysis}

To investigate whether the downregulation of miRNA on chromosome 14q32.31-32.2 is related to structural variation, we analyzed a subset of samples including 57 controls and 81 cases using commercially available TaqMan copy-number assays (Applied Biosystems). Amplicons specific for sequence within maternally expressed gene 3, cluster A and cluster B of the $14 q 32$ region, were analyzed relative to the endogenous control RNase-P. No significant deletion or amplification events were detected in this region in either cases or controls (Supplementary Figure 1).

\section{Target gene and pathway analysis}

To gain some appreciation of the biological implications of the schizophrenia-associated changes in miRNA expression, we examined predicted miRNA targets and their associated pathways to see whether any patterns emerged. The more miRNA binding sites a gene has within its $3^{\prime}$-untranslated region, the more likely it is to be post-transcriptionally regulated. ${ }^{53}$ The target prediction algorithms miRanda ${ }^{51}$ and TargetScan ${ }^{52}$ are capable of identifying those miRNA 
Table 2 miRNA significantly downregulated in schizophrenia compared with non-psychiatric controls

\begin{tabular}{|c|c|c|c|}
\hline miRNA ID & Fold change & q-Value & Chromosomal coordinates \\
\hline hsa-miR-329 & 0.753 & 0 & $\begin{array}{l}\text { hsa-miR-329-1 14: } 101493 \text { 122-101493201 [+] } \\
\text { hsa-miR-329-2 14: } 101493 \text { 437-101493520 [+] }\end{array}$ \\
\hline hsa-miR-31 & 0.754 & 0 & 9: $21512114-21512184[-]$ \\
\hline hsa-miR-409-3p & 0.757 & 0 & 14: $101531637-101531715[+]$ \\
\hline hsa-miR-224 & 0.762 & 0 & $\mathrm{X}: 151127050-151127130[-]$ \\
\hline hsa-miR-432 & 0.763 & 0 & 14: $101350820-101350913[+]$ \\
\hline hsa-miR-487b & 0.764 & 0 & 14: $101512792-101512875[+]$ \\
\hline hsa-miR-134 & 0.764 & 0 & 14: $101521024-101521096[+]$ \\
\hline hsa-miR-431 & 0.765 & 0 & 14: $101347344-101347457[+]$ \\
\hline hsa-miR-150* & 0.771 & 0 & 19: $50004042-50004125[-]$ \\
\hline hsa-miR-99b & 0.783 & 0 & 19: $52195865-52195934[+]$ \\
\hline hsa-miR-1275 & 0.798 & 0 & 6: $33967749-33967828[-]$ \\
\hline hsa-miR-335* & 0.799 & 0 & 7: $130135952-130136045[+]$ \\
\hline hsa-miR-200c & 0.813 & 0 & 12: $7072862-7072929[+]$ \\
\hline hsa-miR-486-3p & 0.815 & 0 & 8: $41517959-41518026[-]$ \\
\hline hsa-miR-29b-1* & 0.817 & 0 & $7: 130562218-130562298[-]$ \\
\hline hsa-miR-16-2* & 0.821 & 0 & 3: $160122533-160122613[+]$ \\
\hline hsa-miR-877 & 0.83 & 0 & 6: $30552109-30552194[+]$ \\
\hline hsa-miR-107 & 0.835 & 0 & 10: $91352504-91352584[-]$ \\
\hline hsa-miR-130b* & 0.839 & 0 & 22: $22007593-22007674[+]$ \\
\hline hsa-miR-544 & 0.843 & 0 & 14: $101514995-101515085[+]$ \\
\hline hsa-miR-342-5p & 0.844 & 0 & 14: $100575992-100576090[+]$ \\
\hline hsa-miR-148b & 0.844 & 0 & 12: $54731000-54731098[+]$ \\
\hline hsa-miR-625* & 0.856 & 0 & 14: $65937820-65937904[+]$ \\
\hline hsa-miR-28-3p & 0.858 & 0 & 3: $188406569-188406654[+]$ \\
\hline hsa-miR-576-5p & 0.86 & 0 & 4: $110409854-110409951[+]$ \\
\hline hsa-miR-151-3p & 0.864 & 0 & 8: $141742663-141742752[-]$ \\
\hline hsa-miR-28-5p & 0.869 & 0 & 3: $188406569-188406654[+]$ \\
\hline hsa-miR-664 & 0.871 & 0 & 1: $220373880-220373961[-]$ \\
\hline hsa-miR-128 & 0.874 & 0 & $\begin{array}{l}\text { hsa-miR-128-1 2: } 136422 \text { 967-136423048 [+] } \\
\text { hsa-miR-128-2 3: } 35785 \text { 968-35 } 786051[+]\end{array}$ \\
\hline hsa-miR-584 & 0.879 & 0 & 5: $148441876-148441972[-]$ \\
\hline hsa-miR-574-3p & 0.883 & 0 & 4: $38869653-38869748[+]$ \\
\hline hsa-miR-181a & 0.913 & 0 & $\begin{array}{l}\text { hsa-miR-181a-1 1: } 198828 \text { 173-198 } 828282[-] \\
\text { hsa-miR-181a-2 9: } 127454 \text { 721-127 } 454830[+]\end{array}$ \\
\hline hsa-miR-30e* & 0.917 & 0 & 1: $41220027-41220118[+]$ \\
\hline hsa-miR-433 & 0.664 & 1.555 & 14: $101348223-101348315[+]$ \\
\hline hsa-miR-654-5p & 0.73 & 1.555 & 14: $101506556-101506636[+]$ \\
\hline hsa-miR-193b & 0.806 & 1.555 & 16: $14397824-14397906[+]$ \\
\hline hsa-miR-485-3p & 0.816 & 1.555 & 14: $101521756-101521828[+]$ \\
\hline hsa-miR-370 & 0.831 & 1.555 & 14: $101377476-101377550[+]$ \\
\hline hsa-miR-340* & 0.854 & 1.555 & 5: $179442303-179442397[-]$ \\
\hline hsa-miR-1271 & 0.854 & 1.555 & 5: $175794949-175795034[+]$ \\
\hline hsa-miR-151 & 0.855 & 1.555 & 8: $141742663-141742752[-]$ \\
\hline hsa-miR-15b* & 0.86 & 1.555 & 3: $160122376-160122473[+]$ \\
\hline hsa-miR-502-3p, hsa-miR-500* & 0.86 & 1.555 & $\mathrm{X}: 49779206-49779291[+]$ \\
\hline hsa-miR-27b & 0.905 & 1.555 & 9: $97847727-97847823[+]$ \\
\hline hsa-miR-199a-3p, hsa-miR-199b-3p & 0.922 & 1.555 & $\begin{array}{l}\text { hsa-miR-199a-1 19: } 10928 \text { 102-10928 } 172[-] \\
\text { hsa-miR-199a-2 1: } 172113675-172113784[-] \\
\text { hsa-miR-199b 9: } 131007000-131007109[-]\end{array}$ \\
\hline hsa-miR-151-5p & 0.933 & 1.555 & 8: $141742663-141742752[-]$ \\
\hline hsa-miR-146a & 0.95 & 1.555 & 5: $159912359-159912457[+]$ \\
\hline hsa-miR-21 & 0.957 & 1.555 & 17: $57918627-57918698[+]$ \\
\hline hsa-miR-30d & 0.959 & 1.555 & 8: $135817119-135817188[-]$ \\
\hline hsa-miR-127-3p & 0.727 & 2.131 & 14: $101349316-101349412[+]$ \\
\hline hsa-miR-98 & 0.82 & 2.131 & X: $53583184-53583302[-]$ \\
\hline hsa-miR-328 & 0.864 & 2.131 & 16: $67236224-67236298[-]$ \\
\hline hsa-miR-181b & 0.875 & 2.131 & $\begin{array}{l}\text { hsa-miR-181b-1 1: } 198828 \text { 002-198 } 828111[-] \\
\text { hsa-miR-181b-2 9: } 127455989-127456077[+]\end{array}$ \\
\hline hsa-miR-378 & 0.882 & 2.131 & 5: $149112388-149112453[+]$ \\
\hline hsa-miR-150 & 0.963 & 2.131 & 19: $50004042-50004125[-]$ \\
\hline hsa-miR-323-3p & 0.796 & 2.74 & 14: $101492069-101492154[+]$ \\
\hline hsa-miR-874 & 0.797 & 2.74 & 5: $136983261-136983338[-]$ \\
\hline hsa-miR-330-3p & 0.857 & 2.74 & 19: $46142252-46142345[-]$ \\
\hline hsa-miR-500 & 0.862 & 2.74 & $\mathrm{X}: 49773039-49773122[+]$ \\
\hline hsa-miR-181a-2* & 0.878 & 2.74 & 9: $127454721-127454830[+]$ \\
\hline
\end{tabular}


Table 2 Continued

\begin{tabular}{|c|c|c|c|}
\hline miRNA ID & Fold change & q-Value & Chromosomal coordinates \\
\hline hsa-miR-146b-5p & 0.912 & 2.74 & 10: $104196269-104196341[+]$ \\
\hline hsa-let-7b & 0.952 & 2.74 & $22: 46509566-46509648[+]$ \\
\hline hsa-miR-25 & 0.956 & 2.74 & 7: $99691183-99691266[-]$ \\
\hline hsa-miR-92a & 0.957 & 2.74 & $\begin{array}{l}\text { hsa-miR-92a-1 13: } 92003 \text { 568-92 } 003645[+] \\
\text { hsa-miR-92a-2 X: } 133303568-133303642[-]\end{array}$ \\
\hline hsa-miR-410 & 0.812 & 3.288 & 14: $101532249-101532328[+]$ \\
\hline hsa-miR-221* & 0.815 & 3.288 & $X: 45605585-45605694[-]$ \\
\hline hsa-miR-942 & 0.825 & 3.288 & 1: $117637265-117637350[+]$ \\
\hline hsa-miR-664* & 0.845 & 3.288 & 1: $220373880-220373961[-]$ \\
\hline hsa-miR-20b & 0.865 & 3.288 & X: $133303839-133303907[-]$ \\
\hline hsa-miR-628-3p & 0.867 & 3.288 & 15: $55665138-55665232[-]$ \\
\hline hsa-miR-152 & 0.892 & 3.288 & 17: $46114527-46114613[-]$ \\
\hline hsa-let-7d & 0.957 & 3.288 & 9: $96941116-96941202[+]$ \\
\hline hsa-miR-154 & 0.766 & 4.484 & 14: $101526092-101526175[+]$ \\
\hline hsa-miR-337-3p & 0.87 & 4.484 & 14: $101340830-101340922[+]$ \\
\hline hsa-miR-505 & 0.884 & 4.484 & $\mathrm{X}: 139006307-139006390[-]$ \\
\hline hsa-miR-625 & 0.897 & 4.484 & 14: $65937820-65937904[+]$ \\
\hline hsa-miR-22* & 0.898 & 4.484 & 17: $1617197-1617281[-]$ \\
\hline hsa-let-7g & 0.965 & 4.484 & 3: $52302294-52302377[-]$ \\
\hline hsa-miR-1301 & 0.869 & 4.853 & 2: $25551509-25551590[-]$ \\
\hline hsa-let-7d* & 0.905 & 4.853 & 9: $96941116-96941202[+]$ \\
\hline hsa-miR-766 & 0.93 & 4.853 & $\mathrm{X}: 118780701-118780811[-]$ \\
\hline hsa-let-7a & 0.971 & 4.853 & $\begin{array}{l}\text { hsa-let-7a-1 9: } 96938239-96938318[+] \\
\text { hsa-let7a-2 11: } 122017 \text { 230-122017 } 301[-] \\
\text { hsa-let7a-3 22: } 46508629-46508702[+]\end{array}$ \\
\hline
\end{tabular}

Abbreviation: miRNA, microRNA.

Differentially expressed miRNA were ranked by significance and then by fold change. miRNA transcribed from the genomic region encompassing 14q32.2-q32.31 were identified with bold font. *Denotes star form of the mature miRNA.

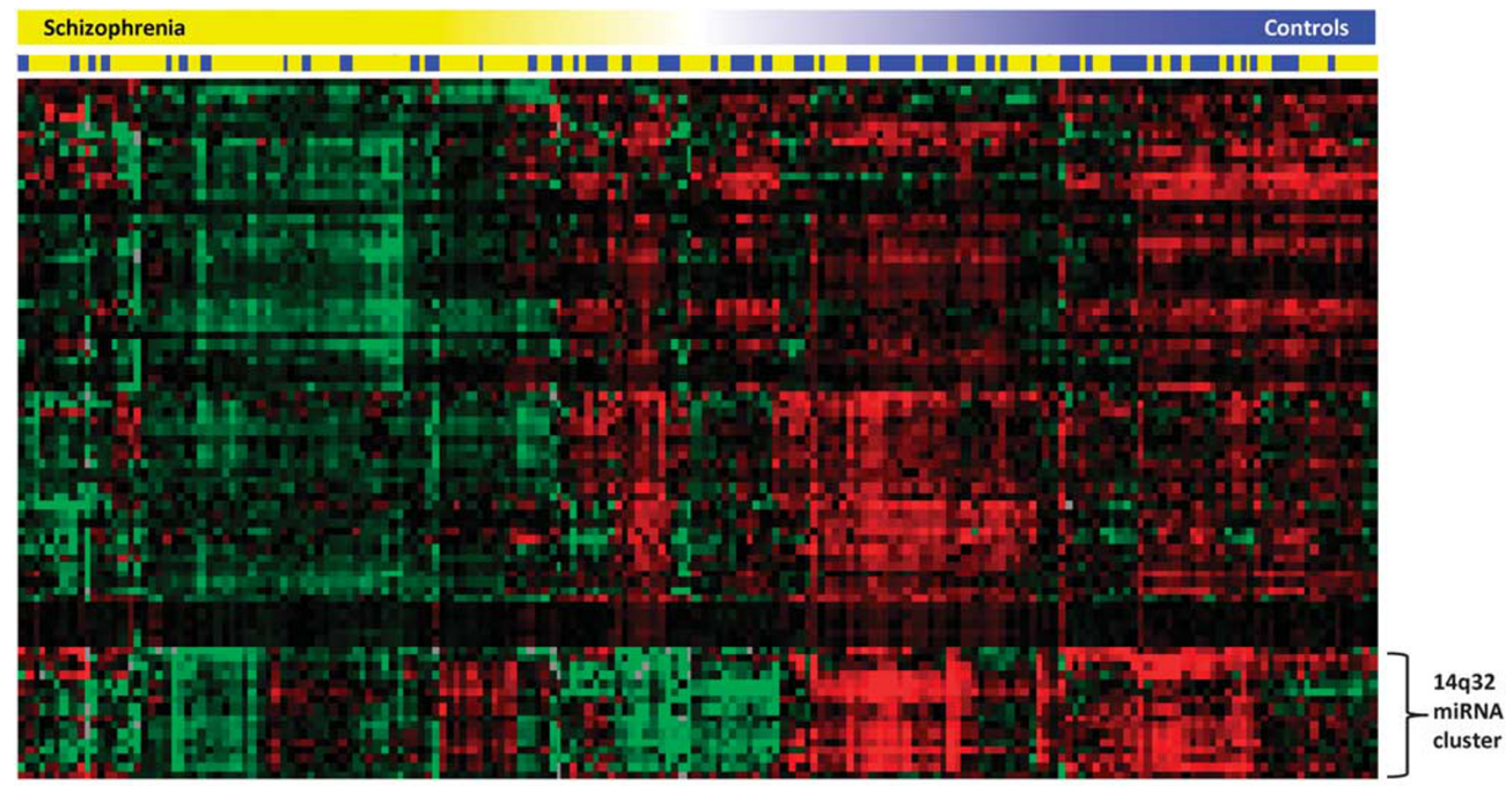

Figure 2 Heatmap showing hierarchical clustering of significantly downregulated microRNA with diagnosis. Samples are color coded according to diagnosis (blue = control; yellow = schizophrenia). Green indicates low expression and red indicates high expression (Java Treeview). 

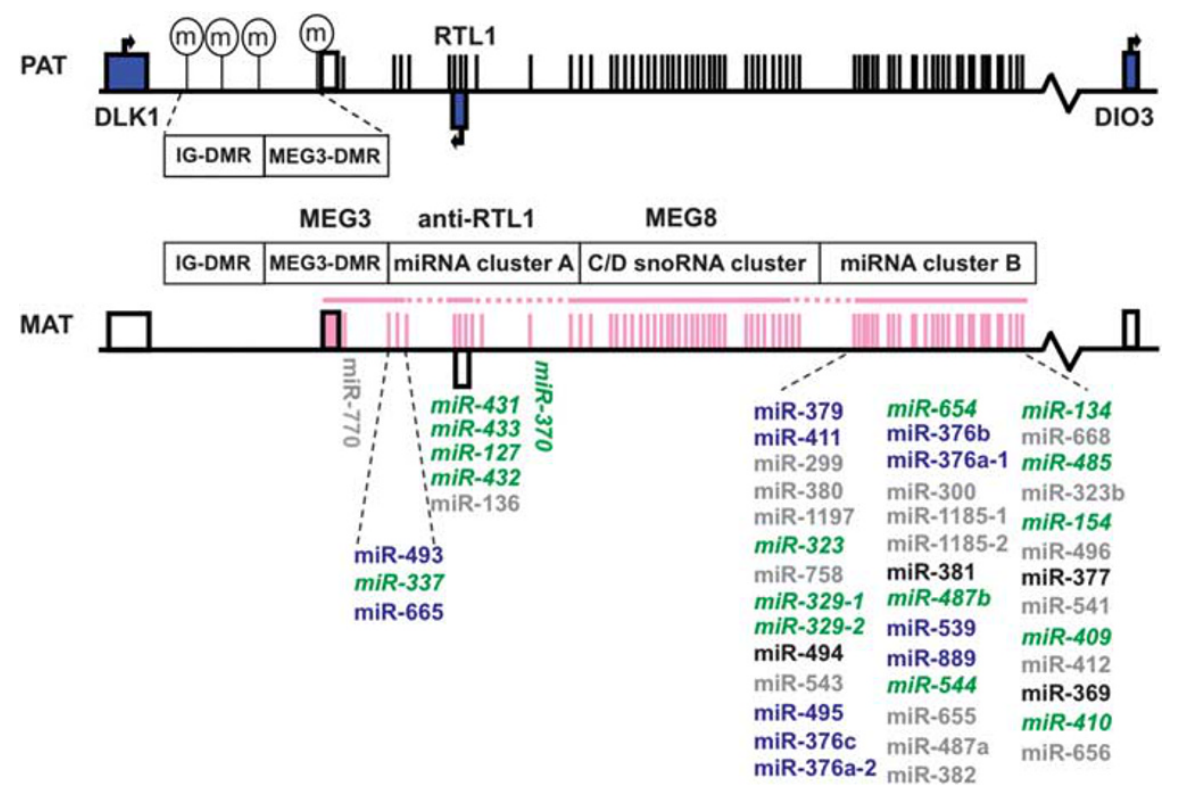

Figure 3 Genomic organization of 14q32 microRNA (miRNA) clusters neighboring the DLK1-DIO3 imprinted domain. DLK1, RTL1 and DIO3 (blue rectangles) are paternally expressed genes. The maternally expressed non-coding RNA genes (pink) include maternally expressed gene 3 (MEG3), anti-RTL1 (encodes the smaller miRNA cluster A), maternally expressed gene 8 (MEG8) (encodes small nucleolar RNA (snoRNA) cluster) and the larger miRNA cluster B. The intergenic germline derived differentially methylated region (IG-DMR) is methylated on the paternal chromosome denoted by the encircled letter $\mathrm{m}$. The 14q32 miRNA clusters are arranged in two segments: each separated by a C/D snoRNA cluster. miRNA in dark green italic font were significantly downregulated in schizophrenia and miRNA in blue exhibited a trend for downregulation in schizophrenia. miRNA in black were expressed but not differentially expressed, and in gray were not expressed. This figure was adapted from Royo and Cavaille ${ }^{64}$ and Hagan et al. ${ }^{103}$

that bind multiple times within the one $3^{\prime}$-untranslated region. As such, this information was used to predict target genes that were most likely to be heavily regulated by the differentially expressed miRNA. Owing to a high degree of false positives, the list of target genes was filtered to only include those genes that were targeted by five or more miRNA, or contained five or more binding sites for a particular miRNA within its $3^{\prime}$-untranslated region. This target analysis process was performed on the 17 miRNA displaying altered expression in the $14 \mathrm{q} 32$ region. The miRanda and TargetScan lists were then combined to form a union of targets predicted by both algorithms in addition to a more stringent analysis involving the intersection of targets identified by both miRanda and TargetScan. Selected genes were then collectively subjected to pathway analysis using the Gene Set Analysis Toolkit V.2 from WebGestalt (http://bioinfo.vanderbilt.edu/webgestalt). ${ }^{54}$ The union of miRanda and TargetScan revealed a number of significantly enriched pathways with relevance to neural connectivity and synaptic plasticity, including axon guidance, long-term potentiation, focal adhesion, neurotrophin, ErbB, calcium and mitogenactivated protein kinase signaling (Table 3 and Supplementary Figure 2). Furthermore, the more stringent intersection approach, using genes predicted to be targets by both algorithms, also suggested the involvement of neurologically relevant pathways as well as pathways relevant to immune system function (Table 4 and Supplementary Figure 3).

\section{Discussion}

A subset of brain-enriched miRNA genes located within a large imprinted cluster on chromosome $14 q 32$ were differentially expressed in schizophrenia

Analysis of post-mortem miRNA expression has previously reported schizophrenia-associated changes in both the superior temporal gyrus and prefrontal cortex. ${ }^{24,47,58}$ Although miRNA expression typically displays a stage- and tissue-specific expression pattern, we identified several brain-enriched miRNAs including miR-134, miR-128 and miR-181b that were also differentially expressed in PBMCs from individuals with schizophrenia. It is plausible that these represent a neurologically relevant signature reflecting the prevailing neuropsychiatric phenotype. The reduction of miR-134 was particularly significant not only because of its role in brain development and function, ${ }^{28,59,60}$ but also as a consequence of its position in a cluster of differentially expressed miRNAs on chromosome $14 \mathrm{q} 32$.

A large proportion of the miRNAs found to be differentially expressed in schizophrenia are encoded within this large cluster on chromosome 14q32, which collectively comprises over $5 \%$ of known human miRNA genes ${ }^{61-63}$ and about $40-50 \%$ of all 
Table 3 Pathways enriched with target genes predicted by a union of miRanda and TargetScan target lists for the 14q32 cluster

\begin{tabular}{|c|c|c|c|c|c|}
\hline Category & Term & $\mathrm{n}$ & $\%$ & $\mathrm{P}$-value & Benjamini \\
\hline KEGG_PATHWAY & Pathways in cancer & 108 & 0.3 & $<0.000$ & $<0.000$ \\
\hline KEGG_PATHWAY & Axon guidance & 54 & 0.1 & $<0.000$ & $<0.000$ \\
\hline KEGG_PATHWAY & Adherens junction & 36 & 0.1 & $<0.000$ & $<0.000$ \\
\hline KEGG_PATHWAY & Regulation of actin cytoskeleton & 72 & 0.2 & $<0.000$ & $<0.000$ \\
\hline KEGG_PATHWAY & Focal adhesion & 68 & 0.2 & $<0.000$ & $<0.000$ \\
\hline KEGG_PATHWAY & Chronic myeloid leukemia & 32 & 0.1 & $<0.000$ & $<0.000$ \\
\hline KEGG_PATHWAY & Insulin signaling pathway & 48 & 0.1 & $<0.000$ & $<0.000$ \\
\hline KEGG_PATHWAY & Renal cell carcinoma & 30 & 0.1 & $<0.000$ & $<0.000$ \\
\hline KEGG_PATHWAY & ErbB signaling pathway & 34 & 0.1 & $<0.000$ & 0.001 \\
\hline KEGG_PATHWAY & MAPK signaling pathway & 79 & 0.2 & $<0.000$ & 0.001 \\
\hline KEGG_PATHWAY & Pancreatic cancer & 29 & 0.1 & $<0.000$ & 0.0016 \\
\hline KEGG_PATHWAY & Ubiquitin-mediated proteolysis & 46 & 0.1 & $<0.000$ & 0.0018 \\
\hline KEGG_PATHWAY & Wnt signaling pathway & 49 & 0.1 & $<0.000$ & 0.0024 \\
\hline KEGG_PATHWAY & Prostate cancer & 33 & 0.1 & $<0.000$ & 0.0023 \\
\hline KEGG_PATHWAY & Long-term potentiation & 27 & 0.1 & $<0.000$ & 0.0028 \\
\hline KEGG_PATHWAY & Glioma & 25 & 0.1 & $<0.000$ & 0.0049 \\
\hline KEGG_PATHWAY & Neurotrophin signaling pathway & 41 & 0.1 & $<0.000$ & 0.0046 \\
\hline KEGG_PATHWAY & Colorectal cancer & 30 & 0.1 & $<0.000$ & 0.0078 \\
\hline KEGG_PATHWAY & mTOR signaling pathway & 21 & 0.1 & 0.0011 & 0.0110 \\
\hline KEGG_PATHWAY & Endocytosis & 54 & 0.1 & 0.0012 & 0.0110 \\
\hline KEGG_PATHWAY & Melanogenesis & 33 & 0.1 & 0.0015 & 0.0130 \\
\hline KEGG_PATHWAY & Calcium signaling pathway & 50 & 0.1 & 0.0039 & 0.0320 \\
\hline KEGG_PATHWAY & Non-small-cell lung cancer & 20 & 0.1 & 0.0047 & 0.0370 \\
\hline KEGG_PATHWAY & Progesterone-mediated oocyte maturation & 28 & 0.1 & 0.0053 & 0.0400 \\
\hline KEGG_PATHWAY & TGF- $\beta$ signaling pathway & 28 & 0.1 & 0.0063 & 0.0460 \\
\hline KEGG_PATHWAY & Melanoma & 24 & 0.1 & 0.0064 & 0.0450 \\
\hline KEGG_PATHWAY & T-cell receptor signaling pathway & 33 & 0.1 & 0.0067 & 0.0450 \\
\hline KEGG_PATHWAY & Jak-STAT signaling pathway & 44 & 0.1 & 0.0070 & 0.0450 \\
\hline KEGG_PATHWAY & Dilated cardiomyopathy & 29 & 0.1 & 0.0073 & 0.0460 \\
\hline KEGG_PATHWAY & HCM & 27 & 0.1 & 0.0089 & 0.0540 \\
\hline KEGG_PATHWAY & Oocyte meiosis & 33 & 0.1 & 0.0090 & 0.0530 \\
\hline
\end{tabular}

Abbreviations: HCM, hypertrophic cardiomyopathy; KEGG, Kyoto Encyclopedia of Genes and Genomes; MAPK, mitogenactivated protein kinase; mTOR, mammalian target of rapamycin; TGF, tumor growth factor.

Enriched KEGG pathways identified by WebGestalt gene set analysis using predicted target genes. The list was compiled from an union of the miRanda and TargetScan predicted targets of 17 members of the miR-14q32 cluster differentially expressed in schizophrenia. $n$, number of input genes in pathway (filtered to only show pathways represented by $\geqslant 7$ target genes). $\%$, percentage of total target genes analyzed ( $\sim 3600$ gene IDs) that are represented in this pathway.

known eutherian-specific miRNA. ${ }^{64}$ Significantly, this locus on 14q32, known as the DLK1-DIO3 region, is imprinted such that the associated miRNA cluster is only expressed from the maternal chromosome. ${ }^{64}$ In mice, the syntenic region on chromosome 12 also resides within an imprinted domain expressed exclusively from the maternal chromosome. ${ }^{57}$ The miRNAs are encoded by two clusters located in close proximity to each other, the smaller of the two at 14q32.2 contains 10 miRNA, which reside within the retrotransposon-like gene RTL1 (in antisense), whereas the larger cluster also known as the miR379-410 cluster contains approximately 40 miRNAs. Although the nature of their organization is not entirely clear in human beings, some of the miRNA in this region could be processed from a single large polycistron such as Mirg (miRNA containing gene, also known as Meg9), which appears to be the case in the mouse. However, it seems more likely that the majority of miRNA in this cluster are encoded by tandem arrays of related intronic sequences. ${ }^{57,65}$

\section{Regulation of the $14 q 32$ miRNA cluster}

As more than $85 \%$ of the miRNAs expressed in this region showed a trend for downregulation in schizophrenia, it is reasonable to suggest that these molecules may be co-regulated by a shared mechanism associated with the disorder. This could relate to a number of common factors that affect transcriptional activity or miRNA processing in this region. Why the remaining miRNAs expressed from this cluster were neutral with respect to disease status remains to be determined, but it could be that the genes encoding these molecules are responding more to differences in their local transcriptional environment, which over-ride the prevailing cluster-wide influence. They may also display isolated differences in their splicing or primary transcript processing, 
Table 4 Pathways enriched with target genes predicted by an intersection of miRanda and TargetScan target lists for the 14 q32 cluster

\begin{tabular}{|c|c|c|c|c|c|}
\hline Category & Term & $\mathrm{n}$ & $\%$ & P-value & Benjamini \\
\hline KEGG_PATHWAY & Pathways in cancer & 31 & 3.8 & $<0.0001$ & $<0.0001$ \\
\hline KEGG_PATHWAY & Prostate cancer & 13 & 1.6 & $<0.0001$ & $<0.0001$ \\
\hline KEGG_PATHWAY & MAPK signaling pathway & 21 & 2.6 & $<0.0001$ & $<0.0001$ \\
\hline KEGG_PATHWAY & Focal adhesion & 18 & 2.2 & $<0.0001$ & $<0.0001$ \\
\hline KEGG_PATHWAY & Melanoma & 11 & 1.4 & $<0.0001$ & $<0.0001$ \\
\hline KEGG_PATHWAY & Adherens junction & 11 & 1.4 & $<0.0001$ & $<0.0001$ \\
\hline KEGG_PATHWAY & Endocytosis & 16 & 2.0 & $<0.0001$ & $<0.0001$ \\
\hline KEGG_PATHWAY & mTOR signaling pathway & 9 & 1.1 & $<0.0001$ & $<0.0001$ \\
\hline KEGG_PATHWAY & Non-small-cell lung cancer & 9 & 1.1 & $<0.0001$ & $<0.0001$ \\
\hline KEGG_PATHWAY & Long-term potentiation & 10 & 1.2 & $<0.0001$ & $<0.0001$ \\
\hline KEGG_PATHWAY & Chronic myeloid leukemia & 10 & 1.2 & $<0.0001$ & $<0.0001$ \\
\hline KEGG_PATHWAY & Insulin signaling pathway & 13 & 1.6 & $<0.0001$ & $<0.0001$ \\
\hline KEGG_PATHWAY & Regulation of actin cytoskeleton & 16 & 2.0 & $<0.0001$ & $<0.0001$ \\
\hline KEGG_PATHWAY & Glioma & 9 & 1.1 & $<0.0001$ & $<0.0001$ \\
\hline KEGG_PATHWAY & Progesterone-mediated oocyte maturation & 10 & 1.2 & $<0.0001$ & $<0.0001$ \\
\hline KEGG_PATHWAY & ErbB signaling pathway & 10 & 1.2 & $<0.0001$ & $<0.0001$ \\
\hline KEGG_PATHWAY & Renal cell carcinoma & 9 & 1.1 & $<0.0001$ & $<0.0001$ \\
\hline KEGG_PATHWAY & Jak-STAT signaling pathway & 13 & 1.6 & $<0.0001$ & $<0.0001$ \\
\hline KEGG_PATHWAY & Pancreatic cancer & 9 & 1.1 & $<0.0001$ & $<0.0001$ \\
\hline KEGG_PATHWAY & Neurotrophin signaling pathway & 11 & 1.4 & $<0.0001$ & $<0.0001$ \\
\hline KEGG_PATHWAY & Colorectal cancer & 9 & 1.1 & $<0.0001$ & $<0.0001$ \\
\hline KEGG_PATHWAY & Small-cell lung cancer & 9 & 1.1 & $<0.0001$ & $<0.0001$ \\
\hline KEGG_PATHWAY & Calcium signaling pathway & 13 & 1.6 & $<0.0001$ & $<0.0001$ \\
\hline KEGG_PATHWAY & TGF- $\beta$ signaling pathway & 9 & 1.1 & $<0.0001$ & $<0.0001$ \\
\hline KEGG_PATHWAY & Dilated cardiomyopathy & 9 & 1.1 & $<0.0001$ & $<0.0001$ \\
\hline KEGG_PATHWAY & Phosphatidylinositol signaling system & 8 & 1.0 & $<0.0001$ & 0.0001 \\
\hline KEGG_PATHWAY & Fc $\gamma$ R-mediated phagocytosis & 9 & 1.1 & $<0.0001$ & 0.0001 \\
\hline KEGG_PATHWAY & Acute myeloid leukemia & 7 & 0.9 & $<0.0001$ & 0.0002 \\
\hline KEGG_PATHWAY & HCM & 8 & 1.0 & 0.0001 & 0.0002 \\
\hline KEGG_PATHWAY & Melanogenesis & 9 & 1.1 & $<0.0001$ & 0.0002 \\
\hline KEGG_PATHWAY & Axon guidance & 10 & 1.2 & 0.0001 & 0.0002 \\
\hline KEGG_PATHWAY & Apoptosis & 8 & 1.0 & 0.0002 & 0.0003 \\
\hline KEGG_PATHWAY & Neuroactive ligand-receptor interaction & 14 & 1.7 & 0.0002 & 0.0003 \\
\hline KEGG_PATHWAY & Vascular smooth muscle contraction & 9 & 1.1 & 0.0002 & 0.0003 \\
\hline KEGG_PATHWAY & Long-term depression & 7 & 0.9 & 0.0003 & 0.0004 \\
\hline KEGG_PATHWAY & Wnt signaling pathway & 10 & 1.2 & 0.0004 & 0.0006 \\
\hline KEGG_PATHWAY & ARVC & 7 & 0.9 & 0.0004 & 0.0006 \\
\hline KEGG_PATHWAY & Fce RI signaling pathway & 7 & 0.9 & 0.0005 & 0.0007 \\
\hline KEGG_PATHWAY & GnRH signaling pathway & 8 & 1.0 & 0.0005 & 0.0007 \\
\hline KEGG_PATHWAY & Tight junction & 9 & 1.1 & 0.0007 & 0.0009 \\
\hline KEGG_PATHWAY & Chemokine signaling pathway & 11 & 1.4 & 0.0007 & 0.0009 \\
\hline KEGG_PATHWAY & T-cell receptor signaling pathway & 8 & 1.0 & 0.0007 & 0.0009 \\
\hline KEGG_PATHWAY & Ubiquitin-mediated proteolysis & 9 & 1.1 & 0.0009 & 0.0011 \\
\hline KEGG_PATHWAY & Oocyte meiosis & 8 & 1.0 & 0.001 & 0.0012 \\
\hline KEGG_PATHWAY & Gap junction & 7 & 0.9 & 0.0012 & 0.0014 \\
\hline KEGG_PATHWAY & Leukocyte transendothelial migration & 8 & 1.0 & 0.0013 & 0.0015 \\
\hline KEGG_PATHWAY & Natural killer cell-mediated cytotoxicity & 8 & 1.0 & 0.0033 & 0.0037 \\
\hline KEGG_PATHWAY & Lysosome & 7 & 0.9 & 0.0052 & 0.0056 \\
\hline KEGG_PATHWAY & Huntington's disease & 9 & 1.1 & 0.0063 & 0.0067 \\
\hline KEGG_PATHWAY & CAMs & 7 & 0.9 & 0.0106 & 0.011 \\
\hline KEGG_PATHWAY & Cytokine-cytokine receptor interaction & 10 & 1.2 & 0.0227 & 0.0231 \\
\hline KEGG_PATHWAY & Metabolic pathways & 29 & 3.6 & 0.0268 & 0.0268 \\
\hline
\end{tabular}

Abbreviations: ARVC, arrhythmogenic right ventricular cardiomyopathy; CAM, cell adhesion molecules; GnRH, gonadotropin-releasing hormone; HCM, hypertrophic cardiomyopathy; KEGG, Kyoto Encyclopedia of Genes and Genomes; MAPK, mitogen-activated protein kinase; mTOR, mammalian target of rapamycin.

Enriched KEGG pathways identified by WebGestalt gene set analysis using predicted target genes. The list was compiled from an intersection of the miRanda and TargetScan predicted targets of 17 members of the miR-14q32 cluster differentially expressed in schizophrenia. $n$, number of input genes in pathway (filtered to only show pathways represented by $\geqslant 7$ target genes). $\%$, percentage of total target genes analyzed ( 810 gene IDs) that are represented in this pathway. 
or pre-miRNA cleavage and maturation. It is also possible that the schizophrenia-associated regulatory influence seen for most of the expressed miRNA extends beyond the miRNA clusters to affect protein coding and other non-coding mRNAs in the region; however, there are no reports to this effect in the schizophrenia literature. A genome-wide study of MS from our laboratory suggests that the proteincoding genes in this domain (DLK1, RTL1, DIO3 and MEG3) are not expressed in lymphocytes. ${ }^{66}$

Studies in the mouse suggest that the expression of miRNA clustered on 14q32 in human beings may be particularly sensitive to changes in the miRNA biogenesis pathway. For example, DiGeorge syndrome critical region gene 8 (DGCR8) heterozygous knockout mice were shown to have significantly reduced levels of mature miRNA expression from the syntenic region on chromosome 12 in both the prefrontal cortex and hippocampus. ${ }^{67}$ The product of this gene, one of many depleted in the 22q11 microdeletion syndromes, is an important component of the microprocessor complex involved in pri-miRNA cleavage in the nucleus. Interestingly, these miRNA were also over represented $(\sim 25 \%)$ among miRNA showing downregulation in dopaminergic neurons from the striatum of Ago2-deficient mice. ${ }^{68}$ A large proportion of miRNA from this cluster also contain primary and secondary structural features associated with dicerindependent/Ago2-slicer activity-dependent processing. ${ }^{69}$ This includes the preponderance for an A/U base at the $5^{\prime}$ terminal in the mature sequence $(80 \%)$ and the preference for miRNA residing in the $3 p$ side of precursor hairpins $(\sim 70 \%) .{ }^{68,70}$ This suggested that Ago2-dependent pre-miRNA processing ${ }^{69,71}$ is particularly important for the biogenesis of miRNA in this cluster and may be associated with changes we observed in schizophrenia. Another possibility is that a 14q32 cluster-associated transcription factor or other regulatory molecule is responsible for the change observed in schizophrenia. One example of this is the $\mathrm{Ca}^{2+}$-activated transcription factor known as myocyte enhancer factor-2 (MEF2), which has been shown to positively regulate expression of miRNA in this cluster. ${ }^{56}$ MEF2 isoforms have also been shown to regulate neuronal development through their role in supporting newly differentiated neurons and synapse formation. ${ }^{72-76}$ We have also shown that expression of the MEF2D isoform is upregulated in differentiating neurons in response to a reduction in miR-17 family miRNA expression. ${ }^{77}$ Lower expression of MEF2 in PBMC could potentially contribute to the reduction in transcription of this cluster in schizophrenia.

\section{Function of $14 q 32$ miRNA cluster in brain function and development}

The miR-379/410 cluster has been shown to follow a similar stage and tissue-specific expression pattern as a colocalized cluster of C/D snoRNAs derived from a single intronic transcript known as maternally expressed gene 8 (RNA imprinted and accumulated in the nucleus on mouse chromosome 12). ${ }^{62}$ This is detectable throughout the developing mouse embryo and the placenta, is enriched in the brain in adult mice mi,57,62,78 $^{29}$ and may be significant for the development of higher brain functions in eutherian mammals. ${ }^{79}$ The neural function of this cluster is supported by recent research suggesting that coordinated expression of these miRNA, including miR-134 and miR-329, is important for brain function and development. Neuronal activity in rats trigger MEF2, a neuronal-activity $\mathrm{Ca}^{2+}$-dependent transcription factor (described above), to bind to sequence upstream of the larger of the two clusters and induce expression of all pre-miRNAs within it. ${ }^{56}$ At least three members of the co-regulated cluster, including miR-329 and miR-134, that we see altered in schizophrenia, appear to regulate hippocampal neuron dendrite morphology. ${ }^{56} \mathrm{MiR}-134$ has also been shown to repress dendritic development by targeting LimK $1^{28}$ and to activate it through targeting Pumilio2. ${ }^{56}$ Interestingly, miR-134 expression is upregulated in the rat hippocampus and amygdala following acute stress, but is decreased during chronic stress. ${ }^{60}$ A predicted target of miR-134, splicing factor SC35, has been shown to be upregulated after stress and is believed to promote alternative splicing of acetylcholinesterase mRNA. Therefore, it is possible that miR134 and other related miRNAs from the 14q32 cluster function as stress-dependent regulators of neurotransmission and synaptic plasticity. This is supported by the pathway analysis of target genes predicted for differentially expressed miRNA in this cluster, which included axon guidance, regulation of the actin cytoskeleton, long-term potentiation, long-term depression, neuroactive ligand-receptor interaction, focal adhesion, neurotrophin, mammalian target of rapamycin, calcium, mitogen-activated protein kinase and ErbB signaling pathways. It was also broadly consistent with previous pathway analysis of the human 14q32 cluster and the syntenic miRNA c luster in the mouse, with enrichment of target genes involved in neurogenesis (including the biological processes in axon guidance), embryonic development and more general developmental processes. ${ }^{79}$ Another interesting theme emerging from the pathway analysis was the large number of immunologically relevant processes including endocytosis, Fc $\gamma$ R-mediated phagocytosis, Fce RI signaling pathway, chemokine signaling pathway, T-cell receptor signaling pathway, leukocyte transendothelial migration and natural killer cell-mediated cytotoxicity. Given the evidence suggesting a link between early environmental exposure to infection/inflammation and schizophrenia, the alteration of miRNA expression in this tissue and their influence in these pathways could have functional significance for the immune system in individuals with the disorder. The expression of miRNA in this cluster was also shown to be highly associated with cellular pluripotency. ${ }^{80}$ If this cluster is involved in the regulation and maintenance of stem cell behavior, the reduction observed in schizophrenia 
could have broad developmental implications for both the immune and nervous systems.

\section{Differentially expressed miRNA are contained within an imprinted locus}

Maternal specific expression of this region is regulated by imprinting centers defined by an intergenic germline derived differentially methylated region (DMR) and the post-fertilization derived MEG3-DMR (shown in Figure 3). ${ }^{81}$ Differential expression of miRNA clustered in this imprinted region raises the possibility that there is a schizophrenia-associated parent of origin effect influencing the miRNA expression from this cluster similar to that observed at a number of other genes including the 5-hydroxytryptamine type $2 \mathrm{~A}$ receptor $^{82}$ and $\mathrm{GABA}_{\mathrm{A}}$ receptor $\beta 2 .{ }^{83}$ Imprinting at the $14 q 32$ region has also been implicated in bipolar disorder ${ }^{84,85}$ and anxiety. ${ }^{86}$ Although no gender bias was observed in the expression of the miRNA cluster, specific details about participants' parental disease status were not sufficient to derive parent of origin effect.

Many characteristics of the imprinted locus on 14q32 parallel the genetic landscape at 15q11-13, known for its involvement in Prader-Willi Syndrome). This neurodevelopmental disorder arises from monoallelic expression at 15q11-13 as a result of deletion of the paternal copy of the imprinted region (delPWS), maternal uniparental disomy (mat-upd-15), as well as abnormal imprinting (reviewed by Buiting ${ }^{87}$ ). The $14 q 32$ and 15q11-13 regions are similar in that they are both developmentally regulated via an imprinting center, and contain both maternally and paternally expressed genes. The imprinted regions of both loci also encode $\mathrm{C} / \mathrm{D}$ snoRNAs that function as guides for epigenetic modification of other RNAs. The snoRNAs in these loci are atypical in that they lack complementarity to their neighboring RNA. These small non-coding RNA molecules, exclusive to eutherians, are also brain enriched and transcribed in the same direction, possibly by a single transcription unit. ${ }^{62,64,88-90}$ In further support of a role for these imprinted loci in neuronal development, Leung et al. ${ }^{90}$ observed developmentally regulated chromatin decondensation of snoRNA clusters at 15q11-13 and 14q32 in postnatal mouse and human neurons.

Individuals with Prader-Willi Syndrome also share some phenotypic features with schizophrenia such as cognitive deficits, behavioral problems and, in some cases, autistic symptoms and psychosis. ${ }^{91-97}$ The 14q32 locus has also been implicated in other disorders with impaired development and behavioral phenotypes. ${ }^{98}$ Rare copy-number variations at $14 q 32$ and 15q11-13 have also been reported in schizophrenia. ${ }^{99-102}$ Although our analysis of copy number in this region did not identify structural variants, this genomic region clearly has the potential to convey risk for neurodevelopmental disorders including schizophrenia.

\section{Conclusions}

In this study, we examined schizophrenia-associated miRNA expression and identified a significant correlation between miRNAs clustered in a small imprinted domain on 14q32. Although the cause of this anomaly is not known, it may be due to an alteration in transcriptional regulation or processing. The miRNAs encoded in this cluster evolved in eutherian mammals and appear to have a significant role in brain development and function. And while the significance of their downregulation in PBMCs in schizophrenia is less clear, there are implications for lymphocyte function that could contribute to the risk for the disorder. Alternatively, this phenomenon may be a vestige of broader alteration to post-transcriptional regulation, with more relevance to neurodevelopment. Regardless of the functional significance, the miRNA expression signatures observed in PBMCs may have the potential to serve as biomarkers of schizophrenia and associated phenotypes.

\section{Conflict of interest}

The authors declare no conflict of interest.

\section{Acknowledgments}

This study was supported by the Schizophrenia Research Institute and the Neurobehavioral Genetics Unit, utilizing funding from NSW Health and an MC Ainsworth Research Fellowship in Epigenetics (MC); a NARSAD Young Investigator Award; a Hunter Medical Research Institute project grant; an NHMRC Project Grant 631057. Samples and clinical and demographic data for this study were provided by the Australian Schizophrenia Research Bank. PBMCs were processed by Melissa Tooney and Janelle Collins-Langworthy. The ASRB is supported by the NHMRC, the Pratt Foundation, Ramsay Health Care and the Schizophrenia Research Institute.

\section{References}

1 Saha S, Chant D, Welham J, McGrath J. A systematic review of the prevalence of schizophrenia. PLoS Med 2005; 2: e141.

2 Nopoulos P, Torres I, Flaum M, Andreasen NC, Ehrhardt JC, Yuh WT. Brain morphology in first-episode schizophrenia. Am J Psychiatry 1995; 152: 1721-1723.

3 Shenton ME, Dickey CC, Frumin M, McCarley RW. A review of MRI findings in schizophrenia. Schizophr Res 2001; 49: 1-52.

4 Weinberger DR, Berman KF, Zec RF. Physiologic dysfunction of dorsolateral prefrontal cortex in schizophrenia. I. Regional cerebral blood flow evidence. Arch Gen Psychiatry 1986; 43: 114-124.

5 McCarley RW, Shenton ME, O’Donnell BF, Faux SF, Kikinis R, Nestor PG et al. Auditory P300 abnormalities and left posterior superior temporal gyrus volume reduction in schizophrenia. Arch Gen Psychiatry 1993; 50: 190-197.

6 Suddath RL, Christison GW, Torrey EF, Casanova MF, Weinberger DR. Anatomical abnormalities in the brains of monozygotic twins discordant for schizophrenia. N Engl J Med 1990; 322: 789-794.

7 Lawrie SM, Hall J, McIntosh AM, Cunningham-Owens DG, Johnstone EC. Neuroimaging and molecular genetics of 
schizophrenia: pathophysiological advances and therapeutic potential. Br J Pharmacol 2008; 153(Suppl 1): S120-S124.

8 Holmes E, Tsang TM, Huang JT, Leweke FM, Koethe D, Gerth CW et al. Metabolic profiling of CSF: evidence that early intervention may impact on disease progression and outcome in schizophrenia. PLoS Med 2006; 3: e327.

9 Killackey E, Yung AR. Effectiveness of early intervention in psychosis. Curr Opin Psychiatry 2007; 20: 121-125.

10 Kawanishi Y, Tachikawa H, Suzuki T. Pharmacogenomics and schizophrenia. Eur I Pharmacol 2000; 410: 227-241.

11 Lakhan SE, Kramer A. Schizophrenia genomics and proteomics: are we any closer to biomarker discovery? Behav Brain Funct 2009; 5: 2

12 Schwarz E, Bahn S. Biomarker discovery in psychiatric disorders. Electrophoresis 2008; 29: 2884-2890.

13 Schwarz E, Bahn S. The utility of biomarker discovery approaches for the detection of disease mechanisms in psychiatric disorders. Br J Pharmacol 2008; 153(Suppl 1): S133-S136.

14 Harrison PJ, Owen MJ. Genes for schizophrenia? Recent findings and their pathophysiological implications. Lancet 2003; 361: 417-419.

15 Altar CA, Jurata LW, Charles V, Lemire A, Liu P, Bukhman Y et al. Deficient hippocampal neuron expression of proteasome, ubiquitin, and mitochondrial genes in multiple schizophrenia cohorts. Biol Psychiatry 2005; 58: 85-96.

16 Aston C, Jiang L, Sokolov BP. Microarray analysis of postmortem temporal cortex from patients with schizophrenia. J Neurosci Res 2004; 77: 858-866.

17 Bowden NA, Scott RJ, Tooney PA. Altered gene expression in the superior temporal gyrus in schizophrenia. BMC Genom 2008; 9: 199.

18 Hakak Y, Walker JR, Li C, Wong WH, Davis KL, Buxbaum JD et al. Genome-wide expression analysis reveals dysregulation of myelination-related genes in chronic schizophrenia. Proc Nat Acad Sci USA 2001; 98: 4746-4751.

19 Mirnics K, Middleton FA, Marquez A, Lewis DA, Levitt P. Molecular characterization of schizophrenia viewed by microarray analysis of gene expression in prefrontal cortex. Neuron 2000; 28: 53-67.

20 Vawter MP, Barrett T, Cheadle C, Sokolov BP, Wood III WH, Donovan DM et al. Application of cDNA microarrays to examine gene expression differences in schizophrenia. Brain Res Bull 2001; 55: 641-650.

21 Vawter MP, Crook JM, Hyde TM, Kleinman JE, Weinberger DR, Becker KG et al. Microarray analysis of gene expression in the prefrontal cortex in schizophrenia: a preliminary study. Schizophr Res 2002; 58: 11-20.

22 Weidenhofer J, Bowden NA, Scott RJ, Tooney PA. Altered gene expression in the amygdala in schizophrenia: up-regulation of genes located in the cytomatrix active zone. Mol Cell Neurosci 2006; 31: 243-250.

23 Beveridge NJ, Gardiner E, Carroll AP, Tooney PA, Cairns MJ. Schizophrenia is associated with an increase in cortical microRNA biogenesis. Mol Psychiatry 2009; 15: 1176-1189.

24 Beveridge NJ, Tooney PA, Carroll AP, Gardiner E, Bowden N, Scott RJ et al. Dysregulation of miRNA 181b in the temporal cortex in schizophrenia. Hum Mol Genet 2008; 17: 1156-1168.

25 Farh KK, Grimson A, Jan C, Lewis BP, Johnston WK, Lim LP et al. The widespread impact of mammalian microRNAs on mRNA repression and evolution. Science (New York, NY) 2005; 310: $1817-1821$

26 Fiore R, Siegel G, Schratt G. MicroRNA function in neuronal development, plasticity and disease. Biochim Biophys Acta 2008; 1779: 471-478.

27 Krichevsky AM, Sonntag KC, Isacson O, Kosik KS. Specific microRNAs modulate embryonic stem cell-derived neurogenesis. Stem cells (Dayton, OH) 2006; 24: 857-864.

28 Schratt GM, Tuebing F, Nigh EA, Kane CG, Sabatini ME, Kiebler M et al. A brain-specific microRNA regulates dendritic spine development. Nature 2006; 439: 283-289.

29 Sempere LF, Freemantle S, Pitha-Rowe I, Moss E, Dmitrovsky E, Ambros V. Expression profiling of mammalian microRNAs uncovers a subset of brain-expressed microRNAs with possible roles in murine and human neuronal differentiation. Genome Biol 2004; 5: R13.

30 Mraz M, Malinova K, Mayer J, Pospisilova S. MicroRNA isolation and stability in stored RNA samples. Biochem Biophys Res Commun 2009; 390: 1-4.

31 Friedman RC, Farh KK, Burge CB, Bartel DP. Most mammalian mRNAs are conserved targets of microRNAs. Genome Res 2009; 19: $92-105$.

32 Lodes MJ, Caraballo M, Suciu D, Munro S, Kumar A, Anderson B. Detection of cancer with serum miRNAs on an oligonucleotide microarray. PLoS One 2009; 4: e6229.

33 Lu J, Getz G, Miska EA, Alvarez-Saavedra E, Lamb J, Peck D et al. MicroRNA expression profiles classify human cancers. Nature 2005; 435: 834-838.

34 Calin GA, Liu CG, Sevignani C, Ferracin M, Felli N, Dumitru CD et al. MicroRNA profiling reveals distinct signatures in B cell chronic lymphocytic leukemias. Proc Natl Acad Sci USA 2004; 101: 11755-11760.

35 Blenkiron C, Goldstein LD, Thorne NP, Spiteri I, Chin SF, Dunning MJ et al. MicroRNA expression profiling of human breast cancer identifies new markers of tumor subtype. Genome Biol 2007; 8: R214.

36 Shi M, Guo N. MicroRNA expression and its implications for the diagnosis and therapeutic strategies of breast cancer. Cancer Treat Rev 2009; 35: 328-334.

37 Iorio MV, Casalini P, Tagliabue E, Menard S, Croce CM. MicroRNA profiling as a tool to understand prognosis, therapy response and resistance in breast cancer. Eur J Cancer 2008; 44: 2753-2759.

38 Cox MB, Cairns MJ, Gandhi KS, Carroll AP, Moscovis S, Stewart GJ et al. MicroRNAs miR-17 and miR-20a inhibit T cell activation genes and are under-expressed in MS whole blood. PLoS One 2010; 5: e12132.

39 Schipper HM, Maes OC, Chertkow HM, Wang E. MicroRNA expression in Alzheimer blood mononuclear cells. Gene Regul Syst Biol 2007; 1: 263-274.

40 Cogswell JP, Ward J, Taylor IA, Waters M, Shi Y, Cannon B et al. Identification of miRNA changes in Alzheimer's disease brain and CSF yields putative biomarkers and insights into disease pathways. J Alzheimer's Dis 2008; 14: 27-41.

41 Brown AS, Derkits EJ. Prenatal infection and schizophrenia: a review of epidemiologic and translational studies. Am J Psychiatry 2010; 167: 261-280.

42 Fatemi SH, Reutiman TJ, Folsom TD, Huang H, Oishi K, Mori S et al. Maternal infection leads to abnormal gene regulation and brain atrophy in mouse offspring: implications for genesis of neurodevelopmental disorders. Schizophr Res 2008; 99: 56-70.

43 Strous RD, Shoenfeld Y. Schizophrenia, autoimmunity and immune system dysregulation: a comprehensive model updated and revisited. J Autoimmun 2006; 27: 71-80.

44 Yolken RH, Torrey EF. Viruses, schizophrenia, and bipolar disorder. Clin Microbiol Rev 1995; 8: 131-145.

45 Castle DJ, Jablensky A, McGrath JJ, Carr V, Morgan V, Waterreus A et al. The diagnostic interview for psychoses (DIP): development, reliability and applications. Psychol Med 2006; 36: 69-80.

46 Loughland C, Draganic D, McCabe K, Richards J, Nasir A, Allen J et al. The Australian Schizophrenia Research Bank: a database of comprehensive clinical, endophenotypic and genetic data for aetiological studies of schizophrenia. Aust N Z J Psychiatry 2010; 44: 1029-1035.

47 Santarelli DM, Beveridge NJ, Tooney PA, Cairns MJ. Upregulation of dicer and microRNA expression in the dorsolateral prefrontal cortex Brodmann area 46 in schizophrenia. Biol Psychiatry 2011; 69: 180-187.

48 Tusher VG, Tibshirani R, Chu G. Significance analysis of microarrays applied to the ionizing radiation response. Proc Natl Acad Sci USA 2001; 98: 5116-5121.

49 Eisen MB, Spellman PT, Brown PO, Botstein D. Cluster analysis and display of genome-wide expression patterns. Proc Natl Acad Sci USA 1998; 95: 14863-14868.

50 Saldanha AJ. Java Treeview-extensible visualization of microarray data. Bioinformatics (Oxford, England) 2004; 20: $3246-3248$. 
51 Enright JB, Aravin AJ, Tuschl T, Sander C, Marks DS. Human microRNA targets. PLoS Biol 2004; 2: e363.

52 Lewis BP, Burge CB, Bartel DP. Conserved seed pairing, often flanked by adenosines, indicates that thousands of human genes are microRNA targets. Cell 2005; 120: 15-20.

53 Hon LS, Zhang Z. The roles of binding site arrangement and combinatorial targeting in microRNA repression of gene expression. Genome Biol 2007; 8: R166.

54 Zhang B, Kirov S, Snoddy J. WebGestalt: an integrated system for exploring gene sets in various biological contexts. Nucleic Acids Res 2005; 33: W741-W748.

55 Merico D, Isserlin R, Stueker O, Emili A, Bader GD. Enrichment map: a network-based method for gene-set enrichment visualization and interpretation. PLoS One 2010; 5: e13984.

56 Fiore R, Khudayberdiev S, Christensen M, Siegel G, Flavell SW, Kim TK et al. Mef2-mediated transcription of the miR379-410 cluster regulates activity-dependent dendritogenesis by fine-tuning Pumilio2 protein levels. EMBO J 2009; 28: 697-710.

57 Seitz H, Royo H, Bortolin ML, Lin SP, Ferguson-Smith AC, Cavaille J. A large imprinted microRNA gene cluster at the mouse Dlk1-Gtl2 domain. Genome Res 2004; 14: 1741-1748.

58 Perkins DO, Jeffries CD, Jarskog LF, Thomson JM, Woods K, Newman MA et al. microRNA expression in the prefrontal cortex of individuals with schizophrenia and schizoaffective disorder. Genome Biol 2007; 8: R27.

59 Khudayberdiev S, Fiore R, Schratt G. MicroRNA as modulators of neuronal responses. Commun Integr Biol 2009; 2: 411-413.

60 Meerson A, Cacheaux L, Goosens KA, Sapolsky RM, Soreq H, Kaufer D. Changes in brain microRNAs contribute to cholinergic stress reactions. J Mol Neurosci 2010; 40: 47-55.

61 Cavaille J. MicroRNAs: biosynthesis: mechanisms of action and biological functions. Ann Pathol 2007; 27: 1S31-1S32.

62 Cavaille J, Seitz H, Paulsen M, Ferguson-Smith AC, Bachellerie JP. Identification of tandemly-repeated C/D snoRNA genes at the imprinted human 14q32 domain reminiscent of those at the Prader-Willi/Angelman syndrome region. Hum Mol Genet 2002; 11: 1527-1538.

63 Kircher M, Bock C, Paulsen M. Structural conservation versus functional divergence of maternally expressed microRNAs in the Dlk1/Gtl2 imprinting region. BMC Genom 2008; 9: 346.

64 Royo H, Cavaille J. Non-coding RNAs in imprinted gene clusters. Biology of the Cell/Under the Auspices of the Eur Cell Biology Organization 2008; 100: 149-166.

65 Seitz H, Youngson N, Lin SP, Dalbert S, Paulsen M, Bachellerie JP et al. Imprinted microRNA genes transcribed antisense to a reciprocally imprinted retrotransposon-like gene. Nat Genet 2003; 34: 261-262.

66 Riveros C, Mellor D, Gandhi KS, McKay FC, Cox MB, Berretta R et al. A transcription factor map as revealed by a genome-wide gene expression analysis of whole-blood mRNA transcriptome in multiple sclerosis. PLoS One 2010; 5: e14176.

67 Stark KL, Xu B, Bagchi A, Lai WS, Liu H, Hsu R et al. Altered brain microRNA biogenesis contributes to phenotypic deficits in a 22q11-deletion mouse model. Nat Genet 2008; 40: 751-760.

68 Schaefer A, Im HI, Veno MT, Fowler CD, Min A, Intrator A et al Argonaute 2 in dopamine 2 receptor-expressing neurons regulates cocaine addiction. I Exp Med 2010; 207: 1843-1851.

69 Diederichs S, Haber DA. Dual role for argonautes in microRNA processing and posttranscriptional regulation of microRNA expression. Cell 2007; 131: 1097-1108.

70 Frank F, Sonenberg N, Nagar B. Structural basis for 5 '-nucleotide base-specific recognition of guide RNA by human AGO2. Nature 2010; 465: 818-822.

71 O'Carroll D, Mecklenbrauker I, Das PP, Santana A, Koenig U, Enright AJ et al. A Slicer-independent role for Argonaute 2 in hematopoiesis and the microRNA pathway. Genes Dev 2007; 21: 1999-2004.

72 Lam BY, Chawla S. MEF2D expression increases during neuronal differentiation of neural progenitor cells and correlates with neurite length. Neurosci Lett 2007; 427: 153-158.

73 Linseman DA, Bartley CM, Le SS, Laessig TA, Bouchard RJ, Meintzer MK et al. Inactivation of the myocyte enhancer factor-2 repressor histone deacetylase- 5 by endogenous $\mathrm{Ca}(2+)$ //calmodulin-dependent kinase II promotes depolarization- mediated cerebellar granule neuron survival. J Biol Chem 2003; 278: 41472-41481.

74 Mao Z, Bonni A, Xia F, Nadal-Vicens M, Greenberg ME. Neuronal activity-dependent cell survival mediated by transcription factor MEF2. Science (New York, NY) 1999; 286: 785-790.

75 Mao Z, Wiedmann M. Calcineurin enhances MEF2 DNA binding activity in calcium-dependent survival of cerebellar granule neurons. J Biol Chem 1999; 274: 31102-31107.

76 Okamoto S, Krainc D, Sherman K, Lipton SA. Antiapoptotic role of the p38 mitogen-activated protein kinase-myocyte enhancer factor 2 transcription factor pathway during neuronal differentiation. Proc Natl Acad Sci USA 2000; 97: 7561-7566.

77 Beveridge NJ, Tooney PA, Carroll AP, Tran N, Cairns MJ. Downregulation of miR-17 family expression in response to retinoic acid induced neuronal differentiation. Cell Signal 2009; 21: 1837-1845

78 Wheeler G, Ntounia-Fousara S, Granda B, Rathjen T, Dalmay T. Identification of new central nervous system specific mouse microRNAs. FEBS Lett 2006; 580: 2195-2200.

79 Glazov EA, McWilliam S, Barris WC, Dalrymple BP. Origin, evolution, and biological role of miRNA cluster in DLK-DIO3 genomic region in placental mammals. Mol Biol Evol 2008; 25: 939-948.

80 Liu L, Luo GZ, Yang W, Zhao X, Zheng Q, Lv Z et al. Activation of the imprinted Dlk1-Dio3 region correlates with pluripotency levels of mouse stem cells. J Biol Chem 2010; 285: 19483-19490.

81 Kagami M, O’Sullivan MJ, Green AJ, Watabe Y, Arisaka O, Masawa $\mathrm{N}$ et al. The IG-DMR and the MEG3-DMR at human chromosome 14q32.2: hierarchical interaction and distinct functional properties as imprinting control centers. PLoS Genet 2010; 6: e1000992.

82 Bunzel R, Blumcke I, Cichon S, Normann S, Schramm J, Propping $\mathrm{P}$ et al. Polymorphic imprinting of the serotonin-2A (5-HT2A) receptor gene in human adult brain. Brain Res 1998; 59: 90-92.

83 Pun FW, Zhao C, Lo WS, Ng SK, Tsang SY, Nimgaonkar V et al. Imprinting in the schizophrenia candidate gene GABRB2 encoding GABA(A) receptor beta(2) subunit. Mol Psychiatry 2010; 16: 557-568.

84 Cichon S, Schumacher J, Muller DJ, Hurter M, Windemuth C, Strauch $\mathrm{K}$ et al. A genome screen for genes predisposing to bipolar affective disorder detects a new susceptibility locus on 8q. Hum Mol Genet 2001; 10: 2933-2944.

85 Segurado R, Detera-Wadleigh SD, Levinson DF, Lewis CM, Gill M, Nurnberger Jr JI et al. Genome scan meta-analysis of schizophrenia and bipolar disorder, part III: bipolar disorder. Am I Hum Genet 2003; 73: 49-62.

86 Middeldorp CM, Hottenga JJ, Slagboom PE, Sullivan PF, de Geus EJ, Posthuma D et al. Linkage on chromosome 14 in a genomewide linkage study of a broad anxiety phenotype. Mol Psychiatry 2008; 13: 84-89.

87 Buiting K. Prader-Willi syndrome and Angelman syndrome. Am J Med Genet C 2010; 154C: 365-376.

88 de los Santos T, Schweizer J, Rees CA, Francke U. Small evolutionarily conserved RNA, resembling C/D box small nucleolar RNA, is transcribed from PWCR1, a novel imprinted gene in the Prader-Willi deletion region, which is highly expressed in brain. Am J Hum Genet 2000; 67: 1067-1082.

89 Johnstone KA, DuBose AJ, Futtner CR, Elmore MD, Brannan CI, Resnick JL. A human imprinting centre demonstrates conserved acquisition but diverged maintenance of imprinting in a mouse model for Angelman syndrome imprinting defects. Hum Mol Genet 2006; 15: 393-404.

90 Leung KN, Vallero RO, DuBose AJ, Resnick JL, LaSalle JM. Imprinting regulates mammalian snoRNA-encoding chromatin decondensation and neuronal nucleolar size. Hum Mol Genet 2009; 18: 4227-4238.

91 Cassidy SB, Dykens E, Williams CA. Prader-Willi and Angelman syndromes: sister imprinted disorders. Am J Med Genet 2000; 97: 136-146.

92 Veltman MW, Craig EE, Bolton PF. Autism spectrum disorders in Prader-Willi and Angelman syndromes: a systematic review. Psychiatric Genet 2005; 15: 243-254. 
93 Whittington J, Holland A, Webb T, Butler J, Clarke D, Boer H. Cognitive abilities and genotype in a population-based sample of people with Prader-Willi syndrome. J Intellect Disabil Res 2004; 48: $172-187$.

94 Holland AJ, Whittington JE, Butler J, Webb T, Boer H, Clarke D. Behavioural phenotypes associated with specific genetic disorders: evidence from a population-based study of people with Prader-Willi syndrome. Psychol Med 2003; 33: 141-153.

95 Jauregi J, Arias C, Vegas O, Alen F, Martinez S, Copet P et al. A neuropsychological assessment of frontal cognitive functions in Prader-Willi syndrome. J Intellect Disabil Res 2007; 51: 350-365.

96 Relkovic D, Doe CM, Humby T, Johnstone KA, Resnick JL, Holland AJ et al. Behavioural and cognitive abnormalities in an imprinting centre deletion mouse model for Prader-Willi syndrome. Eur J Neurosci 2010; 31: 156-164.

97 Soni S, Whittington J, Holland AJ, Webb T, Maina EN, Boer H et al. The phenomenology and diagnosis of psychiatric illness in people with Prader-Willi syndrome. Psychol Med 2008; 38: 1505-1514.

98 Zollino M, Seminara L, Orteschi D, Gobbi G, Giovannini S, Della Giustina E et al. The ring 14 syndrome: clinical and molecular definition. Am J Med Genet A 2009; 149A: 1116-1124.

99 Kirov G, Grozeva D, Norton N, Ivanov D, Mantripragada KK, Holmans $\mathrm{P}$ et al. Support for the involvement of large copy number variants in the pathogenesis of schizophrenia. Hum Mol Genet 2009; 18: 1497-1503.

100 Stefansson H, Rujescu D, Cichon S, Pietilainen OP, Ingason A, Steinberg $\mathrm{S}$ et al. Large recurrent microdeletions associated with schizophrenia. Nature 2008; 455: 232-236.

101 Moon HJ, Yim SV, Lee WK, Jeon YW, Kim YH, Ko YJ et al. Identification of DNA copy-number aberrations by arraycomparative genomic hybridization in patients with schizophrenia. Biochem Biophys Res Commun 2006; 344: 531-539.

102 Xu B, Roos JL, Levy S, van Rensburg EJ, Gogos JA, Karayiorgou M. Strong association of de novo copy number mutations with sporadic schizophrenia. Nat Genet 2008; 40: 880-885.

103 Hagan JP, O’Neill BL, Stewart CL, Kozlov SV, Croce CM. At least ten genes define the imprinted Dlk1-Dio3 cluster on mouse chromosome 12qF1. PLoS One 2009; 4: e4352.

This work is licensed under the Creative Commons Attribution-NonCommercialNo Derivative Works 3.0 Unported License. To view a copy of this license, visit http://creativecommons.org/licenses/by-nc-nd/3.0/

Supplementary Information accompanies the paper on the Molecular Psychiatry website (http://www.nature. $\mathrm{com} / \mathrm{mp}$ ) 